\title{
Glutamate recognition sites in human fetal brain
}

\author{
John D. Barks ${ }^{1}$, Faye S. Silverstein ${ }^{1,2}$, Katherine Sims ${ }^{4}$, \\ J. Timothy Greenamyre ${ }^{2}$ and Michael V. Johnston ${ }^{1-3}$ \\ Departments of 'Pediatrics and ${ }^{2}$ Neurology, and ${ }^{3}$ Center for Human Growth and Development, University \\ of Michigan, Ann Arbor, MI (U.S.A.) and the ${ }^{4}$ E.K. Shriver Center for Mental Retardation, Waltham, MA \\ (U.S.A.)
}

(Received 29 June 1987; Accepted 28 September 1987)

Key words: Glutamate; Human; Fetus; Autoradiography; Hippocampus; Caudate; Globus pallidus

We used in vitro autoradiography with $\left[{ }^{3} \mathrm{H}\right]$ glutamate to examine the distribution of glutamate recognition sites in 18 and 21 week gestation human fetal brains. We found a wide distribution of $\left[{ }^{3} \mathrm{H}\right]$ glutamate binding in both specimens, in a pattern distinct from that reported in adult brain using the same autoradiographic methods. In fetal brain, prominent $\left[{ }^{3} \mathrm{H}\right]$ glutamate binding was evident in hippocampal formation. caudate-putamen, globus pallidus, subthalamic nucleus, reticular nucleus of thalamus and substantia innominata.

Little is known about the developmental time table for glutamatergic pathways in the human brain. Recent reports have described a transient dense expression of glutamate recognition sites in globus pallidus in human infants [7] and transient concentration of kainate binding sites in the dentate gyrus of mid-trimester human fetuses and newborn infants [11].

Currently, there is tremendous clinical interest in understanding the impact of intra-uterine hypoxia and similar metabolic stresses on cerebral development. Since regions with a high concentration of glutamate receptors may be especially vulnerable to selective neuronal injury from hypoxia-ischemia, status epilepticus and hypoglycemia $[9,12,13]$, an understanding of the development of glutamate receptors in fetal brain may be relevant for understanding patterns of cerebral injury.

To learn more about the development of glutamatergic neuronal circuitry in the human fetal nervous system, we used in vitro autoradiography with $\left[{ }^{3} \mathrm{H}\right]$ glutamate to map the distribution of glutamate recognition sites in two human fetal brains (obtained from 18 and 21 week gestation spontaneous abortuses without obvious congenital anomalies).

Coronal and parasagittal frozen brain sections $(20 \mu \mathrm{m})$ were thaw-mounted onto gel-coated slides and incubated with $\left[{ }^{3} \mathrm{H}\right]$ glutamate according to the methods of

Correspondence: M.V. Johnston, Neuroscience Lab Bldg., 1103 E. Huron, Ann Arbor, MI 48104, U.S.A. 
Greenamyre et al. [5]. Briefly, sections were incubated at $2^{\circ} \mathrm{C}$ for $45 \mathrm{~min}$ in $50 \mathrm{mM}$ Tris- $\mathrm{HCl}$ with $2.5 \mathrm{mM} \mathrm{CaCl}$ and a single concentration of $\left[{ }^{3} \mathrm{H}\right]$ glutamate $\left(2.2 \times 10^{6}\right.$ $\mathrm{dpm} / \mathrm{ml}, 27 \mathrm{nM})$. Blanks were prepared by adding excess cold glutamate $(1 \mathrm{mM})$ to the incubation buffer. Following incubation, slides were apposed to ${ }^{3} \mathrm{H}$-sensitive film (LKB) for 18-21 days at $4^{\circ} \mathrm{C}$. Regional anatomy was defined by examination of adjacent Nissl-stained sections.

In both brains, specific $\left[{ }^{3} \mathrm{H}\right]$ glutamate binding was readily visualized in identifiable anatomical structures. Autoradiograms were analyzed with a computer assisted spotdensitometer [1]. $\left[{ }^{3} \mathrm{H}\right]$ Glutamate binding density (pmol/mg protein) was calculated in hippocampal formation, caudate, putamen, globus pallidus, subthalamic nucleus, thalamus, and temporal cortex of both brains, and in amygdala (21-week fetus) and in dentate gyrus, substantia innominata and frontal lobe cortex (18 week fetus) (Table I).

The hippocampal formation was readily identified in both brains and apparent maturational differences were noted between the two specimens. In the 21 -week brain (Fig. 1A) 3 distinct layers of labelling were seen; the molecular layer had the highest concentration of binding sites, the polymorphic layer the lowest. No sections from this specimen included the dentate gyrus. In the 18-week fetus hippocampal tissue integrity was not as well preserved; binding density was lower in dentate gyrus and hippocampal polymorphic layer than in the zone containing the molecular and pyramidal layers (which could not ${ }^{\circ}$ be distinguished). Since the sections from the 21 -week

\section{TABLE I}

\section{[?H]GLUTAMATE BINDING IN HUMAN FETAL BRAIN}

Specific [ $\left.{ }^{3} \mathrm{H}\right] \mathrm{glutamate}$ binding in 18 and 21 week gestation human fetal brain. Values were calculated from autoradiograms using a computerized spot densitometer to compare optical density in regions of interest with that generated by tritium standards (ARC) exposed with the autoradiograms. Values are mean \pm S.D. in $\mathrm{pmol} / \mathrm{mg}$ protein of all sections read. ( $\geqq 40$ readings/region.)

\begin{tabular}{|c|c|c|}
\hline & 18 Week & 21 Week \\
\hline Caudate & $0.186 \pm 0.023$ & $0.115 \pm 0.024$ \\
\hline Putamen & $0.189 \pm 0.044$ & $0.109 \pm 0.023$ \\
\hline Globus pallidus & $0.186 \pm 0.018$ & $0.125 \pm 0.035$ \\
\hline Temporal cortex & $0.210 \pm 0.034$ & $0.123 \pm 0.022$ \\
\hline Frontal cortex & $0.169 \pm 0.033$ & \\
\hline Thalamus & $0.227 \pm 0.031$ & $0.069 \pm 0.020$ \\
\hline Subthalamic nucleus & $0.168 \pm 0.029$ & $0.104 \pm 0.023$ \\
\hline \multicolumn{3}{|l|}{ Hippocampus } \\
\hline (Str. moleculare) & $0.240 \pm 0.052$ & $0.142 \pm 0.025$ \\
\hline \multicolumn{3}{|l|}{ Hippocampus } \\
\hline (Str. pyramidale) & -- & $0.098 \pm 0.023$ \\
\hline Dentate gyrus & $0.116 \pm 0.019$ & \\
\hline Substantia innominata & $0.266 \pm 0.043$ & \\
\hline Amygdala & & $0.111 \pm 0.015$ \\
\hline
\end{tabular}



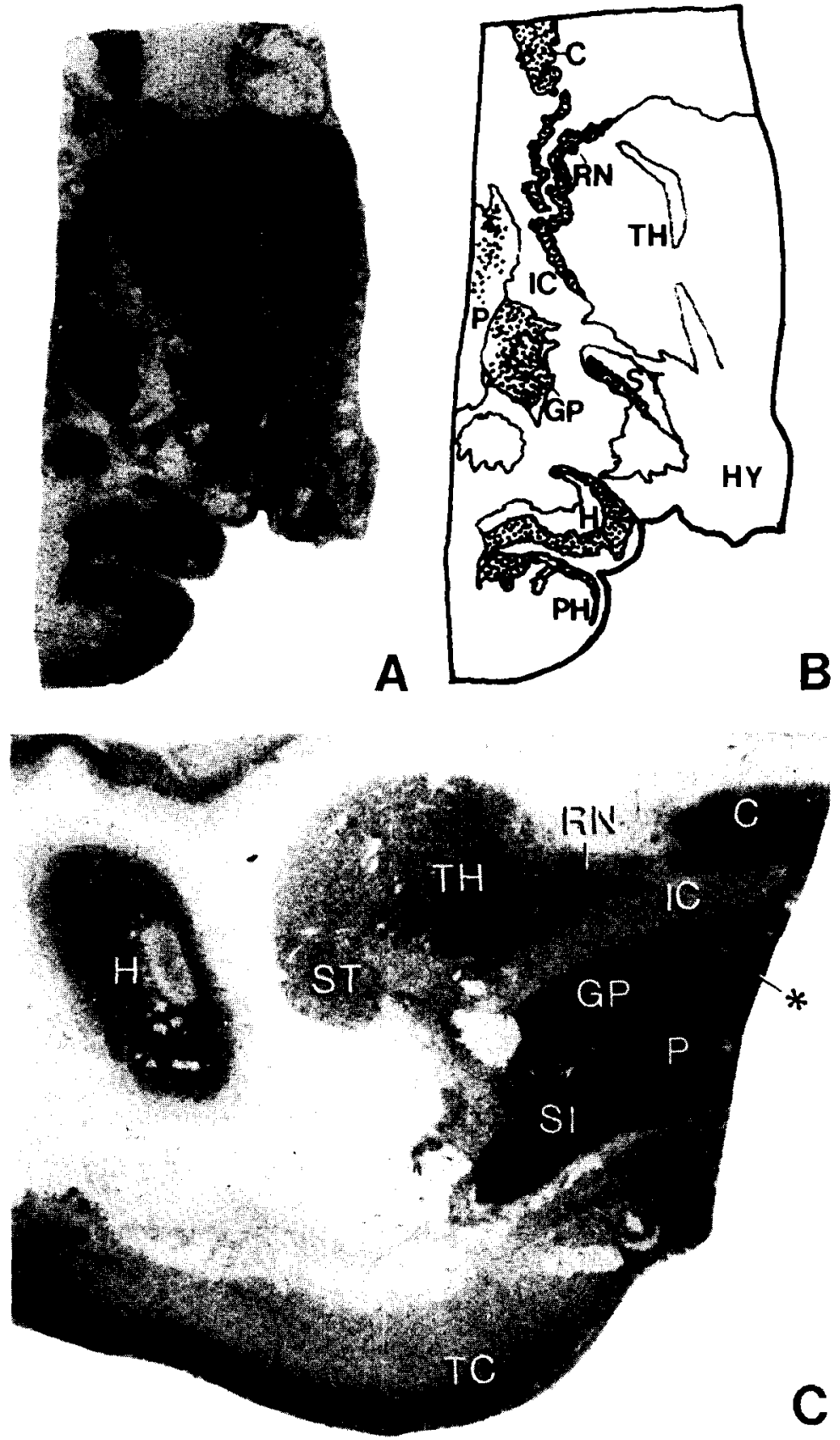

Fig. 1. A: a [ $\left.{ }^{3} \mathrm{H}\right] \mathrm{glutamate}$ autoradiogram of coronal frozen brain section from 21 -week gestation human fetal brain. B: drawing indicating structures of interest in A. C: $\left.{ }^{3} \mathrm{H}\right]$ glutamate autoradiogram of parasagittal frozen brain sections from 18-week gestation human fetal brain. C, caudate; H, hippocampus; GP, globus pallidus; P, putamen; RN, reticular nucleus; SI, substantia innominata; ST. subthalamic nucleus; TC, thalamic cortex; IC, internal capsule. ${ }^{*}$ Indicates patch of increased binding density within caudate. 
fetus did not include dentate gyrus, we could not compare our results directly to those of Represa et al. [11] who commented primarily on the homogeneous high density of kainate receptor binding in this region at 21 weeks.

In the caudate and putamen at both ages, a homogenous background of moderate binding was interrupted by irregular patches of increased labelling. This compartmentalized pattern was confined to the caudate-putamen and was reminiscent of the 'striosomal' distribution of acetylcholinesterase staining described in the caudate of human fetal brain by Graybiel et al. [4, 10]. The striosomal pattern appears to correspond with a compartmentalization of striatal input and output $[3,8]$ and provides evidence of the complex organizational activity present early in fetal brain development.

In the globus pallidus, similar to observations later in infancy, there was a high concentration of glutamate binding sites. Also, of note, was a corresponding high binding density in the subthalamic nucleus which is functionally related to the globus pallidus and which contains few glutamate recognition sites in adult tissue (Greenamyre, Penney, Young, unpublished observations). In substantia innominata (18week fetus, Fig. $1 \mathrm{C}$ ), the $\left[{ }^{3} \mathrm{H}\right]$ glutamate binding density was higher than in adjacent globus pallidum or caudate-putamen. The substantia innominata (containing the nucleus basalis of Meynert) had the highest $\left[{ }^{3} \mathrm{H}\right]$ glutamate binding density of any structure examined in the 18-week brain; in contrast, in the adult brain, there is relatively little $\left[{ }^{3} \mathrm{H}\right]$ glutamate binding in this region [6].

In the thalamus, discrete zones of $\left[{ }^{3} \mathrm{H}\right] \mathrm{glutamate}$ binding that appeared to correspond to specific thalamic nuclei were noted (Fig. 1A). Within thalamus, in both brains, the thin shell-like reticular nucleus had the highest concentration of $\left[{ }^{3} \mathrm{H}\right]$ glutamate binding. This again contrasts with findings observed in adult human brain where this region has one of the lowest binding densities of all thalamic nuclei (Greenamyre, Young, Penney, unpublished observations).

A laminar pattern was discernible in both brains in the temporal lobe cortex. A thin superficial layer had a high binding density, the middle layer had less prominent binding, and the inner-most layer included a broader homogeneous zone of intermediate binding density. These layers corresponded to 3 distinct cortical cell layers in Nissl-stained sections from the 21-week brain but layering could not be identified in the 18 -week brain. Overall, the relative binding densities in temporal cortex vs striatum differed considerably from the relationship observed in adult tissue (fetus 1.1:1 vs adult 1.7:1) [5].

There was little glutamate labelling in the white matter and none in the subependymal germinal layer, which contains a very high concentration of the most immature neurons.

These results demonstrate that glutamate recognition sites are widely distributed in human fetal brain, in a pattern which is distinct from that observed in adult brain tissue using identical autoradiographic methods [5]. These observations provide additional support for the concept of transient, developmentally regulated expression of glutamate recognition sites in specific brain regions, e.g. globus pallidus, subthalamic nucleus and substantia innominata. 
The functional significance of these sites is uncertain. There is little information about human synaptic development in corresponding anatomical regions at this developmental stage. However, our results suggest that expression of excitatory amino acid neurotransmitter recognition sites may be an early feature of synapse formation [14].

In adult brain, hypoxia-ischemia preferentially damages brain regions which are enriched in glutamate receptors. The transient dense glutamatergic innervation of the neonatal globus pallidus may make it particularly vulnerable to glutamate-mediated hypoxic-ischemic injury. Pallidal injury may be the anatomic substrate for the movement disorders which characterize some forms of cerebral palsy. In the majority of children with cerebral palsy, no adverse perinatal events can be documented. If high densities of glutamate receptors render brain regions vulnerable to hypoxic-ischemic injury postnatally, they may play the same role in utero.

There is also experimental evidence that in utero exposure to high maternal dietary intake of glutamate may lead to long-lasting changes in cholinergic and adrenergic function in her offspring [2]. This observation suggests that regions of fetal brain in which glutamate receptors are concentrated may also be vulnerable to influences from maternal diet or defective maternal amino acid metabolism.

Understanding how specific genetic or environmental factors influence the development of glutamate receptors in human fetal brain may provide novel insights into the mechanisms of perinatal brain injury.

A preliminary report of these data was presented at the annual meeting of the Child Neurology Society, Boston, 1986. This work was supported in part by PHS Grant 1 PO1 NS 19613 (M.V.J.) and 1 KO8 NSO1171 (F.S.S.).

1 Dauth, G.W., Frey, K.A. and Gilman, S., A densitometer for quantitative autoradiography, J. Neurosci. Methods. 9 (1986) 243-251.

2 Frieder, B. and Grimm, V.E., Prenatal monosodium glutamate causes long-lasting cholinergic and adrenergic changes in various brain regions, J. Neurochem., 48 (1987) $1359 \quad 1365$.

3 Goldman-Rakic, P.S., Prenatal formation of cortical input and development of cytoarchitectonic compartments in the neostriatum of the rhesus monkey, J. Neurosci., 1 (1981) 721-735.

4 Graybiel, A.M. and Ragsdale, C.W., Jr., Clumping of acetylcholinesterase activity in the developing striatum of the human fetus and young infant. Proc. Natl. Acad. Sci., USA, 77 (1980) $1214 \cdot 1218$.

5 Greenamyre, J.T., Young. A.B. and Penney. J.B., Quantitative autoradiographic distribution of L[ ${ }^{3} \mathrm{H}$ ]glutamate-binding sites in rat central nervous system. J. Neurosci., 4 (1984) 21332144.

6 Greenamyre. J.T., Penney, J.B., Young, A.B., D'Amato, C.J., Hicks, S.P. and Shoulson, I., Alterations in L-glutamate binding in Alzheimer's and Huntington's diseases, Science, 227 (1985) 14961499.

7 Greenamyre, J.T., Penney, J.B., Young, A.B., Hudson, C., Silverstein, F.S. and Johnston. M.V.. Evidence for transient perinatal glutamatergic innervation of globus pallidus, J. Neurosci., 7(4) (1987) $1022-1030$.

8 Lanca, A.I., Boyd, S., Kolb, B.E. and Van der Kooy, D., The development of a patchy organization of the rat striatum, Dev. Brain Res., 27 (1986) 1-10.

9 Meldrum, B., Excitatory amino acids and anoxic/ischemic brain damage, Trends Neurosci., 8 (1985) 47.48

10 Nastuk, M.A. and Graybiel, A.M., Patterns of muscarinic cholinergic binding in the striatum and their relation to dopamine islands and striosomes, J. Comp. Neurol.. 237 (1985) 176-194. 
11 Represa, A., Tremblay, E., Schoevart, D. and Ben-Ari, Y., Development of high affinity kainate binding sites in human and rat hippocampi, Brain Res., 384 (1986) 170-174.

12 Rothman. S.M. and Olney, J.W.. Glutamate and the pathophysiology of hypoxic-ischemic brain damage, Ann. Neurol., 19 (1986) 105111.

13 Silverstein, F.S., Torke, L., Barks, J. and Johnston, M.V., Hypoxia-ischemia produces focal disruption of glutamate receptors in developing brain, Dev. Brain Res. 34 (1987) 33-39.

14 Woodward, D.J., Hoffer, B.J., Siggins, G.R. and Bloom, F.F., The ontogenetic development of synaptic junctions, synaptic activation and responsiveness to neurotransmitters in rat cerebellar Purkinje cells, Brain Res.. 34 (1971) $73-97$. 